\title{
Erratum to: Ketimine Reductase: Reciprocal Control of Thyroid Hormone Binding and the Pipecolate Pathway in Brain
}

\author{
André Hallen $^{1}$ - Arthur J. L. Cooper ${ }^{2}$
}

Published online: 16 March 2017

(C) Springer Science+Business Media New York 2017

\section{Erratum to: Neurochem Res (2017) 42:217-243}

DOI 10.1007/s11064-016-2015-9

The original version of this article unfortunately contained a mistake in the title. The title should be: Ketimine Reductase: Reciprocal Control of Thyroid Hormone Binding and the Pipecolate Pathway in Brain instead of Reciprocal Control of Thyroid Binding and the Pipecolate Pathway in the Brain. The title is corrected with this erratum.

The online version of the original article can be found under doi:10.1007/s11064-016-2015-9.

Arthur J. L. Cooper

arthur_cooper@nymc.edu

André Hallen

andre.hallen@students.mq.edu.au

1 Department of Chemistry and Biomolecular Sciences, Macquarie University, Balaclava Road, North Ryde, Sydney, NSW 2109, Australia

2 Department of Biochemistry and Molecular Biology, New York Medical College, Valhalla, New York 10595, USA 